ORIGINAL ARTICLE

\title{
Empowering Students towards Self-Directed Learning Using Multiple Choice Questions Construction as a Learning Tool in a Private Medical College: A Mixed Quantitative and Qualitative Study
}

Nilofar Mustafa, Shazia Tufail", Maria Ahmad, Quratul Ain Mushtaq, Pakeeza Aslam, Riffat Sarwar

\begin{abstract}
Objective: To determine the effectiveness of Multiple Choice Questions (MCQ) construction as a learning tool for empowering the students towards self-directed learning.

Study Design: Mixed quantitative and qualitative study.

Place and Duration of Study: The study was carried out at Department of Obstetrics and Gynaecology, CMH Lahore Medical College, from $1^{\text {st }}$ April to $30^{\text {th }}$ September 2019.

Materials and Methods: All students of final year MBBS were divided into two groups. After a pre-test (test 1 ) of MCQs, they attended a workshop on construction of MCQs, followed by construction and vetting of MCQs by students. The students took a test (test 2) based on those MCQs and evaluated it, followed by post-test (test 3 ) 08 weeks later to assess deep learning. Semi structured in-depth interviews of 10 randomly selected students based on 10 open ended questions were conducted about their perceptions of learning. Quantitative data analysis was performed using SPSS version 17. A thematic analysis was performed for the qualitative data.

Results: Comparison of pre and post-tests yielded a $p$ value of 0.013 , which is statistically significant. Comparison of the mean results of tests 1 and 2 yielded a $p$ value of 0.001 , which is also statistically significant. The qualitative component of the study revealed that use of MCQ construction to enhance self-directed learning was highly appreciated by the students as a learning tool.

Conclusion: MCQ construction when used as a learning tool improved the self-directed learning of the students. Experience of construction of MCQs enhanced the cognitive skills of the students while being highly acceptable.
\end{abstract}

Key Words: Learning, Learning Tool, Medical Students, Multiple Choice Questions, Psychometrics, Self-Directed Learning.

How to cite this: Mustafa N, Tufail S, Ahmad M, Mushtaq Q, Aslam P, Sarwar R. Empowering Students towards Self-Directed Learning Using Multiple Choice Questions Construction as a Learning Tool in a Private Medical College: A Mixed Quantitative and Qualitative Study. Life and Science. 2022; 3(1): 49-54. doi: http://doi.org/10.37185/LnS.1.1.212

This is an Open Access article distributed under the terms of the Creative Commons Attribution License (http://creativecommons.org/licenses/by/4.0), which permits unrestricted use, distribution, and reproduction in any medium, provided the original work is properly cited.

\section{Introduction}

Self-directed learning (SDL) has been found to be essential in the development and maintenance of professional competence and is the hallmark of best practice. ${ }^{1}$ It is the consequence of allowing learners to make decisions about the information they want

Department of Gynecology and Obstetrics

$\mathrm{CMH}$ Lahore Medical College and Institute of Dentistry, Lahore

Correspondence:

Dr. Shazia Tufail

Associate Professor, Gynaecology and Obstetrics

$\mathrm{CMH}$ Lahore Medical College and Institute of Dentistry, Lahore

E-mail: shazia201007@hotmail.com

Funding Source: NIL; Conflict of Interest: NIL

Received: Jun 04, 2021; Revised: Sep 09, 2021

Accepted: Oct 05, 2021 to experience.

Self-directed learning has earned significance rapidly over the last four decades. This change has resulted from rapid advancement of science in this field. ${ }^{2}$ The terms lifelong learning, deep learning, continuing medical education, active/independent learning, student-centered education are often used synonymously with the term self-directed learning. Current medical education places specific emphasis on self-directed learning skills and their acquisition both by the students as well as by the faculty. Problem-based curricula in particular utilize the SDL skills. The Alliance for Continuing Medical Education Tri nation alliance (ACME-TRI) Report identified that 
it should be the foremost duty of the faculty to inculcate the habit of self-directed learning in the students and help them become lifelong learners. ${ }^{3}$

It is now being increasingly recognized that assessment acts as a driving force behind learning. ${ }^{4,5}$ However, there is a paucity of local publications that shed light on the relationship between assessment and learning. A good assessment tool is MCQ used in all types of psychometric testing. ${ }^{6}$ It can help assess the knowledge of a student and the depth of his understanding of the subject in a quick and unbiased way. Moreover, the results of one MCQ do not affect that of the other thus independent assessment can be done. Multiple choice questions are a good learning tool for the students because firstly they read the text and in this way may cover a major portion of the curriculum. Secondly, if the MCQ construction is used as a learning tool, this helps them learn what is the basic concept behind an MCQ and subconsciously they start to filter text and select substances that can come as an MCQ. Also, their problem-solving ability based on the curriculum is greatly enhanced. ${ }^{7,8}$

Our professional examination system in Pakistan comprises of One-Best MCQs, Short answer questions (SAQs) and Objective structured performance examination (OSPE). As assessment drives learning, we presumed that by giving students an opportunity to assess themselves would consequently improve performance. Hence, OneBest MCQs were selected as a study tool. It was hypothesized that when MCQ construction is used as a learning tool, it enhances the self-directed learning of the students. ${ }^{8}$ As construction of One-Best MCQs requires an in-depth knowledge of the subject, therefore by constructing One-Best MCQs, they not only improve their self-directed learning but would also acquire skills to construct One-Best MCQs which help them in future as medical teachers. ${ }^{9}$ When the students attempt One-Best MCQs constructed by their peers, they engage in critical analysis. ${ }^{10}$ They recognize their strengths and weaknesses. Thus, by using this assessment tool, they not only learn from their peers but eventually learn the subject in depth. Therefore, the study was carried out to determine the effectiveness of MCQ construction as a learning tool for empowering the students towards selfdirected learning.

\section{Materials and Methods}

After approval from ethical review committee (Ref No 400/ERC/CMHLMC), this mixed method study was conducted at Department of Obstetrics and Gynaecology, CMH Lahore Medical College, Lahore from $1^{\text {st }}$ April to $30^{\text {th }}$ September 2019 including all students of final year MBBS through non probability purposive sampling. Total population sampling technique was followed for the study. ${ }^{11}$ The primary objective was to assess effectiveness of MCQ construction as a learning tool while the secondary objective was to assess usefulness of MCQ construction in self-directed learning. Students were informed about the purpose of the study, ensuring anonymity and confidentiality and it was made clear that the results of the study would be published for educational purposes. After written informed consent, students were divided with equal number of gender distribution into two groups, $A$ and $B$. A pre-test (test 1 ) of one hour duration was conducted comprising of $50 \mathrm{MCQ}$ s to both the groups out of five selected topics from gynaecology/obstetrics known to them. The topics selected were clinically significant and frequently encountered. After declaration of pre-test result, a workshop of three hours duration supplemented with printed guidelines was held on construction of MCQs. Each group ( $A$ and $B$ ) was subdivided into five subgroups having 10 students, who worked in harmony. After the workshop, each student constructed one new MCQ with a clinical scenario based on the 5 topics. Hence, group A constructed 50 MCQs and so did the group B. Vetting of each $\mathrm{MCQ}$, based on guidelines provided in workshop, was done by the students in 2 sessions. Both groups had separate vetting sessions to maintain confidentiality. After a week, a test (test 2 ) was conducted in such a way that the MCQs of group A were given to group $B$ and vice versa. This test was evaluated by the students. The post-test (test 3) was conducted eight weeks later. The results of the post-test were compared with the pre-test applying paired samples $t$ test. Afterwards, semi structured in-depth interviews of 10 randomly selected volunteer students were conducted about their perceptions of learning. For this interview, a standardized list of 10 open ended questions was used. 


\section{Data Analysis}

Data analysis was performed using SPSS version 17. Paired samples $t$ test was used to compare the means of pre and post-tests of continuous data, considering statistical $p$ value of $<0.05$ as statistically significant. A thematic analysis was performed for the qualitative data (Fig 1).

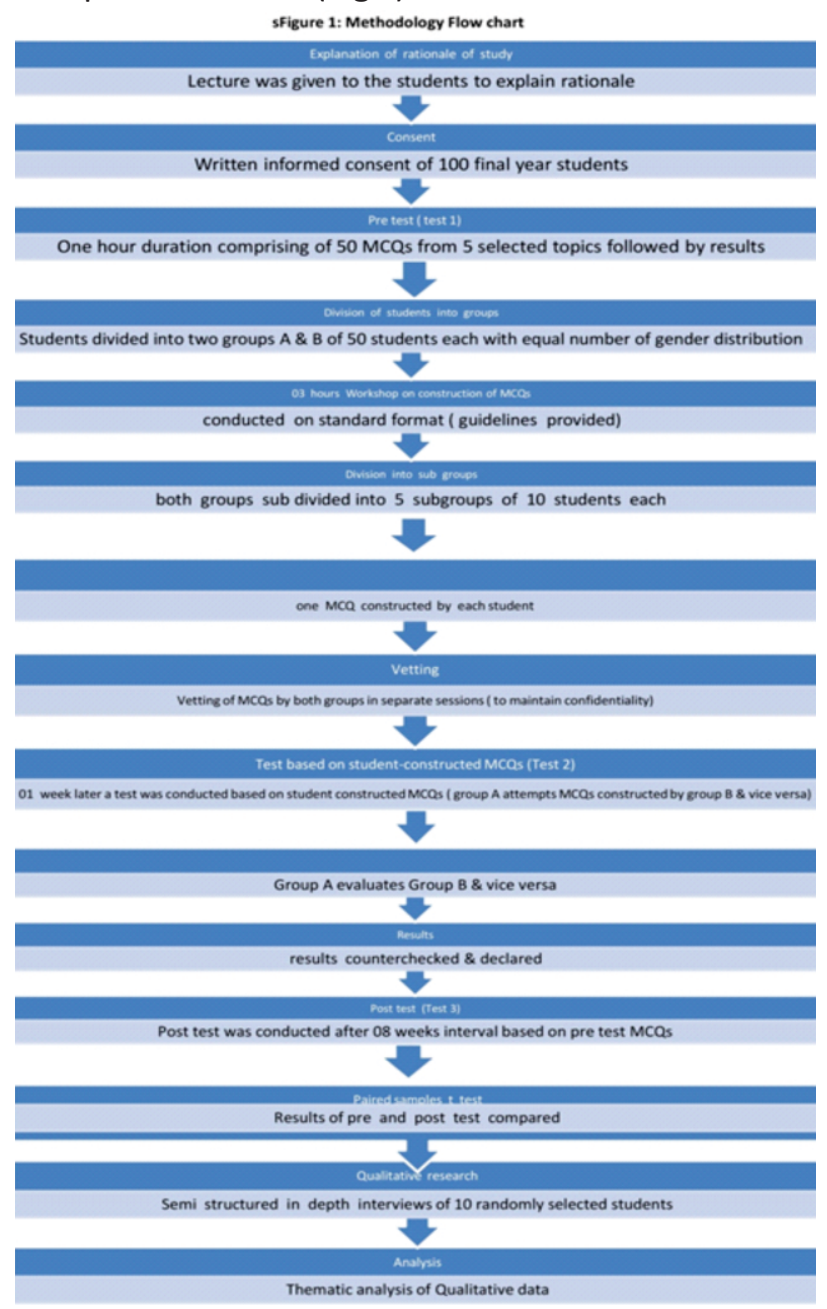

\section{Results}

A total of $100(100 \%)$ medical students participated in the study. There were no dropouts. There were $39(39 \%)$ male and $61(61 \%)$ female students altogether, out of which $32(32 \%)$ belonged to rural and $68(68 \%)$ had an urban background.

The highest score attained by a student in pre-test (test 1 ) was $39 / 50$ and the minimum score was $8 / 50$. The mean score in test 1 was $28.08 \pm 6.6$. The highest score attained by a student in test 2 which was taken 1 week after One-Best MCQ construction was 49/50 and the minimum was $9 / 50$. The mean score in test 2 was $33.66 \pm 8.0$. Comparison of the mean results of tests 1 and 2 using paired sample t-test yielded a statistically significant $p$ value of 0.001 (Table 1 ).

\begin{tabular}{lcc}
\hline \multicolumn{3}{l}{ Table 1: Comparison of the results of Test $\mathbf{1}$ and Test $\mathbf{2}$} \\
\hline & Results of Test $\mathbf{1}$ & Results of Test $\mathbf{2}$ \\
$\mathrm{N}$ Valid & 100 & 100 \\
Missing & 0 & 0 \\
Mean $\pm \underline{\mathrm{SD}}$ & $28.08 \pm 6.64$ & $33.66 \pm 8.06$ \\
Median & 30.50 & 35 \\
Mode & 31 & 39 \\
Range & 31 & 40 \\
Minimum & 8 & 9 \\
Maximum & 39 & 49 \\
$P$ Value & & 0.001 \\
\hline
\end{tabular}

In the post-test (test 3) taken 8 weeks after the workshop, the mean score was comparable i.e., 33.66 in test 2 and $30.18+8.3$ in test 3. Comparison of test 1 and test 3 also yielded a statistically significant $p$ value of 0.013 (Table 2).

\begin{tabular}{|c|c|c|}
\hline & Results of pre test & Results of post test \\
\hline N Valid & 100 & 100 \\
\hline Missing & 0 & 0 \\
\hline Mean \pm SD & $28.08 \pm 6.64$ & $30.18 \pm 8.30$ \\
\hline Median & 30.50 & 30.00 \\
\hline Mode & 31 & 30 \\
\hline Range & 31 & 40 \\
\hline Minimum & 8 & 7 \\
\hline Maximum & 39 & 47 \\
\hline$P$ value & & 0.013 \\
\hline
\end{tabular}

Thematic analysis of the semi-structured interviews revealed that $100 \%$ of students expressed the experience of MCQ construction to be a new and effective learning tool. Majority of them thought that their understanding of the topic improved markedly by this exercise. $80 \%$ did not find MCQ construction to be technically difficult but thought that it was time consuming. No negative peer pressure was reported during the exercise, but lack of cooperation by the peers was felt by $50 \%$. The students expressed that it was a good learning tool to be incorporated into their curriculum. All of them had an idea that SDL needs students themselves to be active learners and agreed that the exercise motivated them towards SDL (Table 3 ).

\section{Discussion}

This study was carried out to determine the effectiveness of MCQ construction as a learning tool 


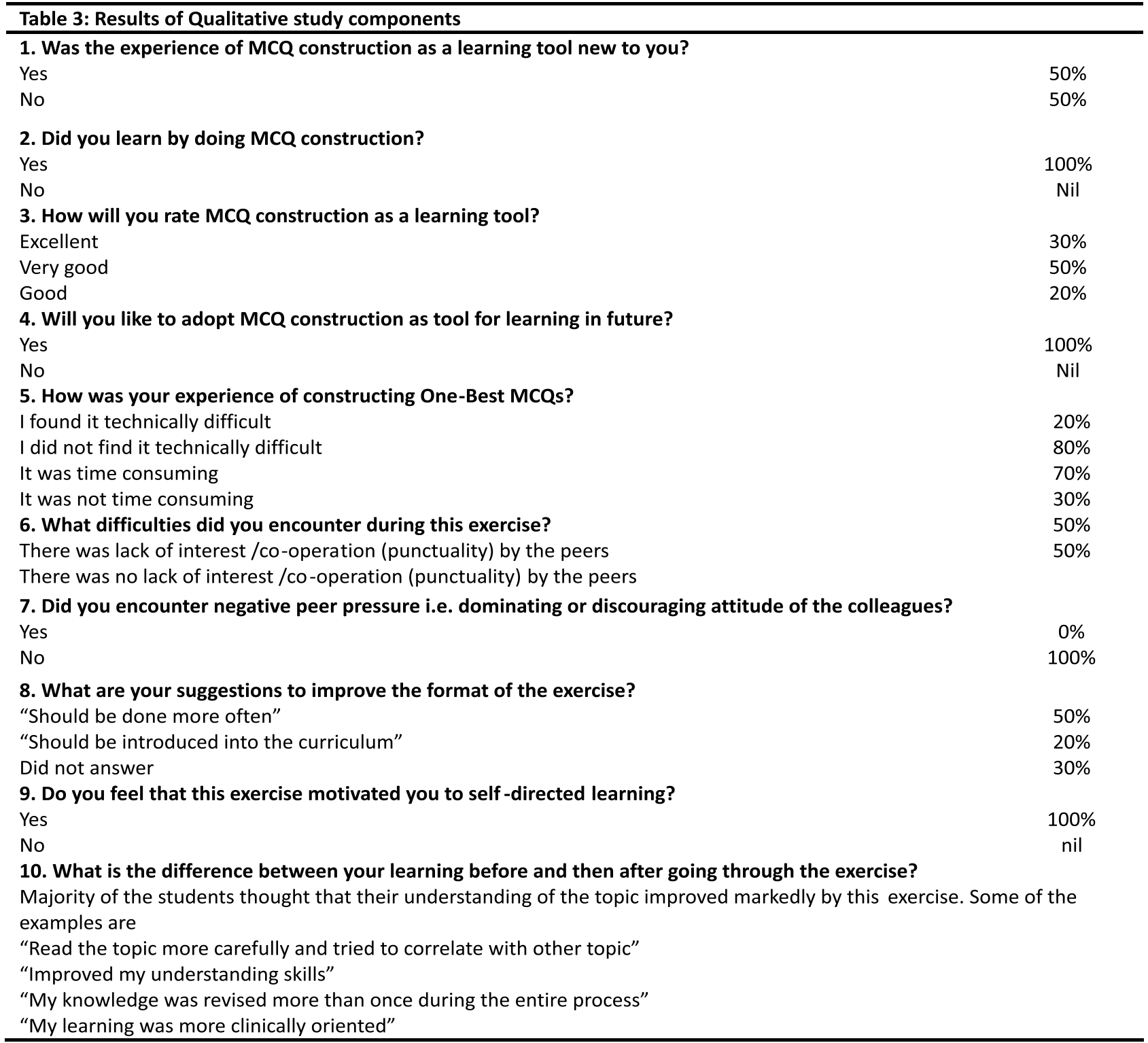

empowering the students towards self-directed learning. We selected construction of One-Best MCQs as a learning tool and it was revealed that MCQ construction at the level of application of knowledge helped the students to improve higher order thinking. Majority of our students had an urban background and even those with a rural domicile had actually completed their secondary and higher secondary school education in urban set ups. So, the population of our study reflects a group of students with strong educational background, well versed with modern assessment techniques e.g. MCQs. A pilot study based on MCQ construction by students was conducted by Grainger to enhance their critical higher order thinking skills. ${ }^{12}$ However, no local or regional study was found on the subject making the current study first ever endeavour on this important subject.

Denny et al., who studied the use of online MCQs for formative assessment, have also suggested MCQs as a tool for improving self-directed learning. This is comparable to our study where we also found construction of MCQs useful as a way of enhancing self-directed learning. ${ }^{13}$

Creating One-Best MCQs not only improves student performance but also motivates them for in-depth study and thus self-directed learning. This was similarly demonstrated by Denny et al. in their research on an MCQ system for peer assessment called Peer Wise, where merely the activities of 
creating and answering One-Best MCQs resulted in improved non-MCQ performance, and a high engagement with Peer Wise. This engagement suggested the development of a deeper level of understanding, enabling improved exam performance. $^{14}$

Regarding quality of One-Best MCQs, in our study we found that One-Best MCQs created by the students were well-structured and they followed the construction guidelines appropriately after the workshop. This is comparable to inference drawn by Denny et al. in their study where they found that students can create a rich and interesting question bank that is an appropriate learning and revision tool for the local teaching context. ${ }^{15}$

In our study, the mean score of students has increased from pre-test to post-test with a statistically significant $p$ value. Similarly, the highest scores in the test have also increased from pre-test to post-test, which is again a marker of improvement in knowledge. These scores were obtained by different students. When compared to study by Damien ${ }^{16}$ the increase in mean score from pre to post test was 4.57 marks, which is comparable to ours. However, in our study, students themselves constructed and vetted One-Best MCQs. The minimum score in our study has remained the same, thus showing that we need more tools other than MCQ construction to show a significant change in improvement in students' knowledge. It is also possible that MCQ construction affects average and above average students, since their knowledge base and probably motivation are better than those who are low performers. The scores of test 2 were slightly better than those of test 3 probably because of the shorter time interval between the One-Best MCQ construction and the test. The knowledge was revised through the exercise and the test depicted better results due to short term retention of knowledge. ${ }^{17}$

Test 3 was conducted 8 weeks after the test 2 . The mean test score showed an improvement when compared to pre- workshop One-Best MCQ test (test 1). Overall the results of test 3 are comparable to test 2. Even after a lapse of 08 weeks, substantial amount of knowledge is retained due to experiential learning. This clearly shows that when gained knowledge is actively utilized, as in construction of One-Best MCQs, it is reproducible after a reasonable time interval. The results are comparable to multiple studies in which a statistically significant improvement in academic performance was revealed when students generated MCQs themselves. ${ }^{18-21}$

During qualitative component of the study, all of them felt that their learning skills improved following this exercise. This result is comparable to the review by Topping, ${ }^{22}$ which suggested that peer assessment using marks, grades and tests has positive effect on students but evidence from other types of assessment like presentation skills and project work is limited. Hanrahan and Isaacs obtained feedback from 233 students regarding self and peer assessment after MCQ construction and the results show that students felt that they benefited from the intervention but training or other measures to further involve the students in such activities might be beneficial. ${ }^{23}$

Students thought that they gained more in depth knowledge by doing $\mathrm{MCQ}$ construction. Race et al comment that MCQ construction promotes deep learning. All students in his study rated MCQ construction as good, very good or excellent and no one said anything negative about it. ${ }^{24}$

They were taught One-Best MCQ construction for the first time but they grasped the concept well and only $20 \%$ found it technically challenging. However majority agreed that this task was time consuming. This can be rectified by repetition and introduction of MCQ construction at an earlier level in their curriculum. This was even suggested by the students themselves. Palmer and Devitt also found that construction of MCQs as a learning tool is an unfamiliar exercise to most students but they are capable of producing high quality questions. ${ }^{25}$ Our students also thought that MCQ construction was somewhat difficult and an unfamiliar learning strategy for them and same result was obtained in the studies by Shakurnia et al. and Kurtz. ${ }^{21}$

This study is a small endeavour towards introduction of SDL and formative assessment among undergraduate medical students in Pakistan. The major limitation of our study is the limited sample size. The study has been conducted in one institution only including 100 undergraduate medical students. The results are therefore not generalizable to the whole community. As there is scarcity of data 
collected on this subject locally as well as regionally, so the comparison of the results has been done only with limited studies. For multiple and widened sampling at all levels, there is a need for larger study with greater sample size.

\section{Conclusion}

Although the study was of a short time frame, students grasped the concept well and produced better results as reflected by the increase in mean score. MCQ construction by the students promoted active learning allowing them to make conceptual connections but demands ample time and knowledge base. The study indicates that active learning of a subject is essential for the students if they are to become life-long self-directed learners and $\mathrm{MCQ}$ construction may prove effective in improving students' learning.

\section{Recommendations}

New learning tools should be explored to inculcate in-depth learning which may promote self-directed learning in the learners. Further multiple center research is also needed on the subject to corroborate the evidence.

\section{REFERENCES}

1. Swanwick T, McKimm J. ABC of clinical leadership. Chichester: Blackwell Publishing Limited; 2011.

2. Custers EJFM, Boshuizen HPA. Psychology of learning. In: Norman GR, van der Vleuten, CPM, Newble DI, editors. International handbook of research in medical education. Dordrecht: Kluwer Academic Publishers, 2002; p. 192.

3. Rehman R, Iqbal A, Syed S, Kamran A. Evaluation of integrated learning program of undergraduate medical students. Pak J Physiol. 2011; 7: 37-41.

4. Khan JS, Biggs JSG, Tabassum S. Assessment in medical education in the $21^{\text {st }}$ century. J Ayub Med Coll Abbottabad. 2010; 22: 3-4.

5. Khan JS. Assessment driven integrated learning (ADIL): Assessment directed medical education (ADME) curriculum. J Ayub Med Coll Abbottabad. 2010; 22: 205-9.

6. Song D. Student-generated questioning and quality questions: a literature review. Res J Educ Stud Rev. 2016; 2: 58-70.

7. Palmer E, Devitt P. Constructing multiple choice questions as a method for learning. Ann Acad Med Singap. 2006; 35: 604-8.

8. Yu FY, Wu CP. Student question-generation: the learning processes involved and their relationships with students' perceived value. J Res Edu Sci. 2012; 57: 135-62.

9. Olde Bekkink M, Donders AR, Kooloos JG, de Waal RMW, Ruiter DJ. Challenging students to formulate written questions: a randomized controlled trial to assess learning effects. BMC Med Educ. 2015; 15: 56.

10. Andrade H, Du Y. Student responses to criteria-referenced self-Assessment. Assess Eval High Educ. 2007; 32: 159-81.

11. Stephanie Glen. "About / Contact" From StatisticsHowTo.com: Elementary Statistics for the rest of us! https://www.statisticshowto.com/contact/. [Accessed on May 30, 2019]

12. Grainger R, Dai W, Osborne E, Kenwright D. Medical students create multiple-choice questions in pathology education: a pilot study. BMC Med Educ. 2018; 18: 201.

13. Denny P, Hanks B, Simon B. PeerWise: Replication study of a student collaborative self-testing web service in a U.S. setting. Proceedings of the 41st ACM Technical Symposium on Computer Science Education New York, NY: ACM. 2010; p. 421-5.

14. Denny P, Luxton-Reilly A, Simon B. Quality of student contributed questions using PeerWise, January. In: M. Hamilton, T. Clear, editors. Eleventh Australasian Computing Education Conference (ACE 2009). Vol. 95 of CRPIT Wellington, New Zealand: Australian Computer Society, 2009; p. 55-64.

15. Denny P, Luxton-Reilly A, Hamer J, Purchase H. Coverage of course topics in a student generated MCQ repository. ITiCSE'09: Proceedings of the 14th annual ACM SIGCSE conference on Innovation and technology in computer science education. New York: ACM, 2009; p. 11-15.

16. Hutchinson D, Wells J. An inquiry into the student generated MCQs as a method of assessment to improve teaching and learning. Creat Educ. 2013; 4: 117-25.

17. Stanton F, Grant J. Approaches to experiential learning, course delivery and validation in medicine. A background document. Med Educ. 1999; 33: 282-97.

18. Doyle E, Buckley P. The impact of co-creation: an analysis of the effectiveness of student authored multiple choice questions on achievement of learning outcomes. Interactive Learning Environments. 2020: 1-0.

19. Sibomana I, Karenzie ID, Niyongombwa I, Byiringiro JC, Gashegu J, Faustin N. Use of Student-generated Multiple Choice Questions to Enhance Team-based Learning of Anatomy at the University of Rwanda. Adv Med Educ Pract. 2020; 11: 825-32.

20. Shakurnia A, Aslami M, Bijanzadeh M . The effect of question generation activity on students' learning and perception. J Adv Med Educ Prof. 2018; 6: 70-7.

21. Kurtz JB, Lourie MA, Holman EE, Grob KL. Creating assessments as an active learning strategy: what are students' perceptions? A mixed methods study. Med Educ Online. 2019; 4: 1630239.

22. Topping K. Peer assessment between students in colleges and universities. Rev Educ Res. 1998; 68: 249-76.

23. Hanrahan SJ, Isaacs G. Assessing self- and peer-assessmentThe students' views. High Educ Res Dev. 2001; 1: 53-70.

24. Race P, Brown S, Smith B. 500 Tips on Assessment. 2nd ed. London: Routledge-Falmer; 2005.

25. Palmer E, Devitt P. Constructing multiple choice questions as a method for learning. Ann Acad Med Singap. 2006; 35: 604-8. 